\title{
A failure to obtain disinhibition in fixed-interval operant conditioning'
}

\author{
ALLEN H. WOLACH and DOUGLASP \\ FERRARO, University of New Mexico, \\ Albuquerque, N. M. 87106
}

Rats were intermittently presented with novel auditory stimuli of different intensities after lever-press responding had stabilized under a FI 1-min reinforcement schedule. External inhibition of the FI scallop was directly related to stimulus intensity when the novel stimulus was presented for an entire interval or for only the second or last fifth of an interval. No evidence for disinhibition of the F1 scallop was obtained.

The similarity between the response patterns obtained in long-delay classical conditioning and fixed-interval operant conditioning is well established. Under both paradigms, the probability of a response is low during the initial portion of the interval and increases as the in terval elapses, reaching a maximum at the end of the interval. This response pattern has been described as "inhibition of delay" in the classical paradigm (Pavlov, 1927) and as "scalloping" in the operant paradigm (Ferster \& Skinner, 1957). Pavlov (1927) demonstrated that the introduction of a nonaversive novel stimulus during the CS.US delay interval disrupted the typical response pattern in a manner dependent upon the intensity of the novel stimulus. A moderately intense stimulus increased responding early in the interval (disinhibition) and decreased responding later in the interval (external inhibition). Low-intensity stimuli produced only disinhibition and high-intensity stimuli produced only external inhibition.

Kimble (1961) has suggested that demonstrations of analogous novel stimulus disinhibition and external inhibition effects on fixed interval scallops would indicate that the similarity between response patterns in long-delay and fixed-interval conditioning is more than superficial. Three experiments, explicitly designed to investigate the effects of a single intensity novel stimulus on fixed-interval responding, have demonstrated disinhibition and external inhibition effects analogous to those produced by a moderately intense stimulus in the long-delay classical paradigm (Flanagan \& Webb, 1964; Hinrichs, 1968; Singh \& Wickens, 1968). The later research is impressive in view of the reported difficulty of obtaining disinhibition in instrumental and operant conditioning when nonaversive novel stimuli are employed (e.g., Horns \& Heron, 1940; Yamaguchi \& Ladioray, 1962; Rexroad, 1937; Skinner, 1936). The present experiments were performed to investigate parametrically the generality of novel stimulus effects in fixed-interval responding by introducing novel auditory stimuli of various intensities during fixed-interval operant conditioning.

\section{EXPERIMENT 1 Method}

Eight 115-day-old naive male Wistar rats, maintained at $80 \%$ of their normal body weight by limiting water intake, served as $\mathrm{Ss}$. The experimental chambers were four Scientific Prototype sound-attenuated rat boxes. Each chamber was equipped with a response lever, speaker, and Lehigh Valley water dipper, and was ventilated by a fan which provided a $58 \mathrm{~dB}$ (re .0002 dyne/ $\mathrm{cm}^{2}$ ) masking noise. Reinforcement consisted of $3-\mathrm{sec}$ access to the dipper which contained $.02 \mathrm{cc}$ of tap water.

Subjects were trained to press the lever and then given five consecutive daily sessions in which each of the first 100 lever-press responses was followed by reinforcement. Ss were then shifted directly to a 1 -min fixed-interval (FI) reinforcement schedule for 24 consecutive daily sessions of 100 reinforcements each. Under the FI schedule, $S$ was rewarded for the first response after the termination of a $1-\mathrm{min}$ interval timed from the previous reinforcement. Lever presses in successive fifths of the $1-$ min interval were cumulated across the 100 intervals of a session.

The last five FI sessions (20-24) served as test sessions. During each test session, a four-click/sec auditory stimulus was presented throughout five of the 1-min fixed intervals. Intervals accompanied by the click stimulus were separated by at least 11 intervals not containing the test stimulus. The three intervals immediately before and after a test interval were used to assess baseline response rates. Each of five click intensities was presented once each session. The sequences of click intensity presentations were randomized over the five test sessions. Click intensities employed were 65 , $66,67,68$, and $69 \mathrm{~dB}$ (re $.0002 \mathrm{dyne} / \mathrm{cm}^{2}$ ) as calibrated at the response lever in the presence of the ventilation fan.

\section{RESULTS}

During the test sessions, each S exhibited a pronounced FI scallop within each 1-min interval not accompanied by a test stimulus.
Number of responses in successive fifths of the three intervals immediately before and after each test interval did not differ across Ss. Consequently, these data were combined for comparison with responding in successive fifths of the test intervals. Figure 1 presents for each click intensity the change in number of responses from the composite baseline obtained during the first, third, and fifth 12-sec period of each test interval. Within the range of stimulus intensities used, the introduction of a novel stimulus during a 1-min FI had no effect on responding early in the interval $(0-12 \mathrm{sec})$. However, during the middle and last fifth of the interval responding was determined, in part, by the intensity of the novel stimulus employed. Although there is some indication of disinhibition at the lower stimulus intensities during the middle fifth of intervals serving as test intervals, the major effect is that of a decrease in responding during the last fifth of the interval (external inhibition) as a function of stimulus intensity. Comparisons of test responding against baseline responding using Dunnett's test for multiple comparisons with a control showed that only the changes at 68 and $69 \mathrm{~dB}$ during the last fifth of the interval were significant $(\mathrm{t}=2.8,3.0 ; \mathrm{df}=234 ; \mathrm{p}<.05)$.

EXPERIMENT 2

Method and Results

At the termination of Experiment 1, all Ss were given four additional sessions of FI 1 -min reinforcement. During the third and fourth sessions, six of the 100 fixed intervals/session were accompanied throughout by a $1000-\mathrm{Hz}$ pure tone. Tone intensity for one-half of the test intervals was $62 \mathrm{~dB}$ and for the other half, the stimulus intensity was $68 \mathrm{~dB}$. The restrictions on time and sequencing of test

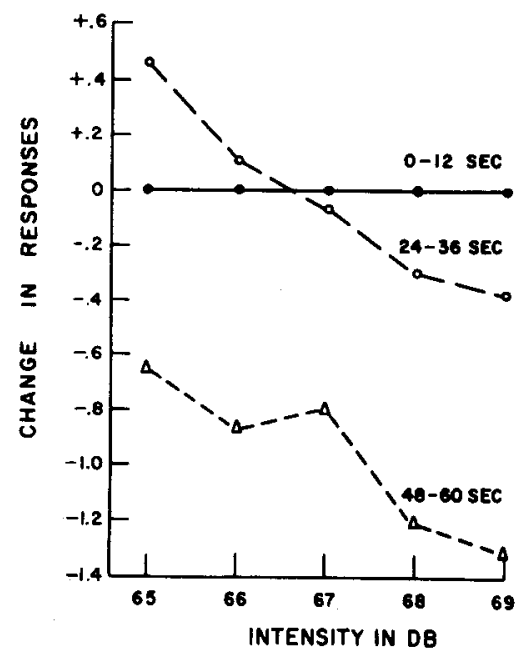

Fig. 1. Average change in responses from baseline for first, third, and last fifth of test intervals at each stimulus intensity. 


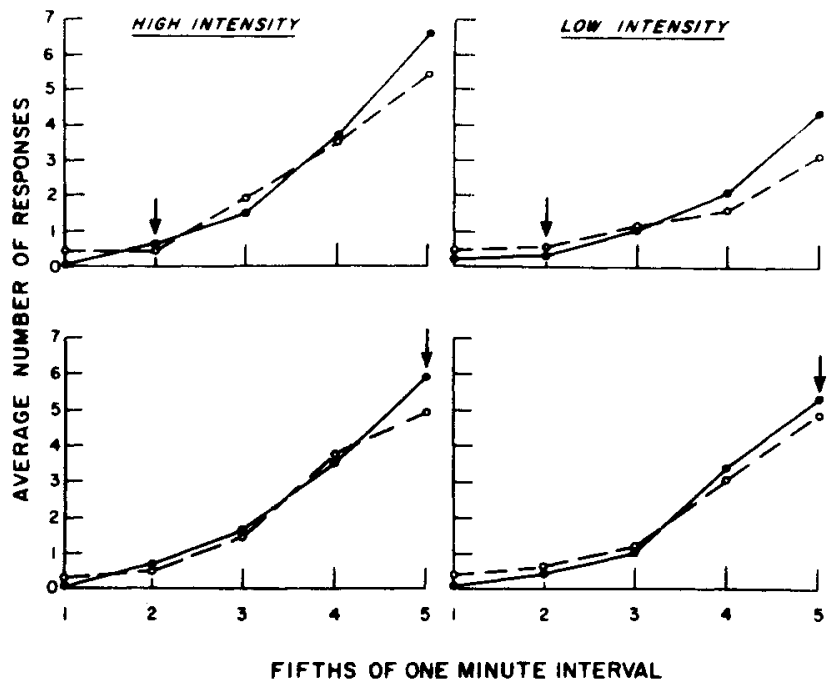

Fig. 2. Average number of baseline responses (solid line) and test responses (dashed line) for successive fifths of a 1 -min fixed interval. Portion of interval during which test stimulus was presented is indicated by the arrow in each panel.

stimulus presentations utilized in Experiment 1 were maintained

Comparisons of responding during the three pre- and posttest intervals again yielded no difference. Deviations of responding from baseline responding during successive fifths of the test intervals were subsequently computed for each stimulus intensity. The only significant deviation obtained was a suppression of responding at the high tone intensity during the last fifth of the test interval $(t=1.33, d f=93$, $\mathrm{p}<.05)$.

\section{EXPERIMENT 3}

Method

Sixteen 140-day-old naive female Wistar rats were reduced to $80 \%$ body weight and trained to make the lever-press response. All Ss were then given five consecutive daily sessions of continuous reinforcement followed by 12 sessions of FI 1 -min reinforcement. Each session was terminated after 100 reinforcements had been delivered. The Ss were then subdivided in to four equal experimental groups on the basis of response rate and response pattern. Two additional FI reinforcement sessions served as test sessions. During these test sessions, five of the 1001 -min fixed intervals were randomly designated as test intervals during which a four-click/sec stimulus was presented. The four groups differed in the intensity and time of presentation of the test stimulus. Stimulus intensity was $65 \mathrm{~dB}$ for two of the groups and $69 \mathrm{~dB}$ for the remaining two groups. One of the two groups at each click intensity was presented with the click stimulus during only the second fifth of a test interval, and the other group at each intensity received the click stimulus during only the last fifth of a tes interval.

\section{RESULTS}

Figure 2 presents the average number of responses for successive fifths of the $1-\mathrm{min}$ fixed interval obtained during the test intervals and during the three baseline intervals before and after each test interval. The only consistent effect to be observed across groups is that the presentation of a novel stimulus for either the second or last fifth of the fixed interval produced a suppression of responding (external inhibition) relative to baseline responding during the last fifth of the interval. This suppression was significant at the .05 level for both high intensity novel stimuli (second fif th, $t=3.3$, $\mathrm{df}=78$; last fifth, $\mathrm{t}=3.1$ ) and for the low intensity, second fifth stimulus $(t=2.9)$. As in the previous two experiments, no significant evidence for disinhibition of responding early in the fixed interval was obtained.

\section{DISCUSSION}

The results of the present experiments demonstrate that introducing a novel auditory stimulus for an entire fixed interval, or for only the early or last portions of the interval, produces a decrement in operant FI responding during the last portion of the interval which is directly related to the intensity of the novel stimulus. These results are in accord with Pavlov's (1927) findings that external inhibition in long-delay classical conditioning is directly related to novel stimulus intensity and that the "aftereffects" of a stimulus present only early in the CS-US interval can inhibit later responding. The similarity of novel stimulus effects in long-delay and fixed-interval conditioning suggests that a comparable inhibitory mechanism may be involved in both classical and operant conditioning paradigms (Kimble, 1961).

It should be noted, however, that stimulus intensities which did not produce significant external inhibition in the present experiment also did not produce disinhibition as would be expected from Pavlov (1927). Extrapolation of the curves in Fig. 1 suggests that if a significant disinhibition effect were, indeed, obtainable under the present procedure, this effect would occur at a stimulus intensity considerably below that which produced external inhibition (cf. Yamaguchi \& Ladioray, 1962). It may be that previous failures to obtain disinhibition of operant extinction (e.g., Skinner, 1936) were related to the intensities of the novel stimuli employed.

It is perhaps more important to note that apparently no single stimulus would reliably produce both disinhibition and external inhibition effects. This finding limits the generality of previous demonstrations of disinhibition and external inhibition in FI conditioning produced by a single novel auditory stimulus within the range of intensities employed here (Flanagan \& Webb, 1964; Singh \& Wickens, 1968). It should be noted that direct comparisons with these previous findings are difficult to make because of several procedural differences other than novel stimulus intensity (e.g., length of Fl training, explicit discrimination training). Nevertheless, the present failure to obtain disuhibition in FI operant conditioning serves to question the correspondence of possible inhibitory mechanisms in classical and operant conditioning.

\section{REI:ERENCIS}

FERSTIR, C. B.. \& SKINNIER, B. F. Schedules of reinforcement. New York: Appleton-CenturyCrofts, 1957.

II ANAGAN, B., \& WEBB, W. B. Disinhibition and external inhibition in tixed interval operant conditioning. Psychonomic Science, 1964, 1. 123-124.

IINRICHS. J. V. Disinhibition of delay in ficed-interval instrumental conditioning. Psychonomic Science. 1968, 12.313.314.

HORNS. H. L., \& HIERON. W. T. A study of disinhibition in the white rat. Joumal of ( omparative Psychology, 1940. 30, 97-102.

KINBI I. ( $i$. A. Hilgard and Marquis "onditioning and k'arning. New York: SpplitontienturyCrots 196.).

PAVIOOV. I. P. Cimlisioned reflexes (translated ly (i. V. Anrep). I ondon: Ovford L'niversity PIs 1927 
RIXROAU, (. N. Reaction time and conditioning: lixtinction, recovery, and disinhibition. Joumal of F xperimental Psy chology, 1937, 20 , 468.476.

SINGH, D, \& WICKENS, D, D. Disinhibition in instrumental conditioning. Journal of Comparative \& Phy siological Psy chology, 1968, 66, 557-559.

SKINNER, B, I. A failure to obtain "disinhibition." Journal of General Psy chology, 1936, 14, 127-135.
YAMAGUCHI, H. G., \& LADIORAY, G. Disinhibition as a function of extinction trials and stimulus in tensity. Journal of ('omparative \& Physiological Psy chology, 1962, 55, 572-577.

\section{NOTI}

1. This investigation was supported by Grant GB7674 from the National Science Foundation. Reprints may be obtained from D.P. Ferraro, Department of Psychology, University of New Mexico, Albuquerque, New Mexico 87106.

\section{Learned resistance to punishment and subsequent responsiveness to the same and novel punishments}

WILLIAM TERRIS, DePaul University, Chicago, Ill. 60614 and MICHAEL BARNES, ${ }^{2}$ University of Oklahoma, Norman, Okla. 73069

In a factorial study, rats were trained to approach and consume food in the presence of gradually increasing shock punishment, gradually increasing airblast punishment, or no punishment, and were subsequently tested with full-strength shock of airblast punishment. The results showed that rats could learn 10 resist intense shock or airblast punishmont if they were introduced gradually. While Ss learning to resist shock showed an increased resistance to airblast there was no evidence of the corresponding generalization from airblast to shock.

Miller (1960) has shown that rats could be trained to resist the effects of intense electric shock if the punishment was introduced gradually with in the context of a rewarded response. Terris \& Wechkin (1967) found that rats learning to resist the effects of mild punishment showed increased resistance to more intense punishments. This learned resistance to punishment was not limited to the uriginal aversive stimulus but incluted novel punishments as well.

The purpose of the present sludy was to replicate the study by Terris and Wechkin in a situation where electric shock and airblast punishment are gradually introduced within the context of a rewarded response. It was hypothesized that $\mathrm{Ss}$ learming to resist the effects of gradual shock, or gradual airblast punishment, would show increased resistance to both shock and airblast punishment. METHOD

The $\mathrm{Ss}$ were 48 naive male Holtzman albino rats, weighing $340-370 \mathrm{~g}$ at the beginning of the experiment. They were housed in group cages and had free access to water throughout the experiment. Five days prior to runway training, the $S$ s were put on a $221 / 2-h$ food deprivation schedule which was maintained throughout the experiment.

The main apparatus was a straight-alley runway $36 \times 4 \frac{1}{2} \times 5$ in., constructed of frosted Plexiglas walls with a hinged, clear Plexiglas top. The entire floor consisted of 1/8-in. stainless-steel rods with the centers placed $3 / 8$ in. apart. Placing an animal into the start end of the runway interrupted a photocell beam and activated a standard electric timer which could be terminated manually. The shock source has been described elsewhere (Terris \& Enzie. 1967) and airblast was delivered from an air gun having a source pressure adjustable from $0-30$ psi and an opening of $1 / 8$ in. in diam. The airblast was administered from behind the food cup and approximately 2 in. from the nuse of the $S$.

The experiment was divided into three phases: (1) approach training, (2) resistance trailing. and (3) punishment testing. Approach training in the runway took place on Days 1-6 of the experiment. On Day 1 each $S$ was given me trial which consisted of placing the $S$ into the runway and allowing a maximum of $5 \mathrm{~min}$ to approach the food and hegin eating from a

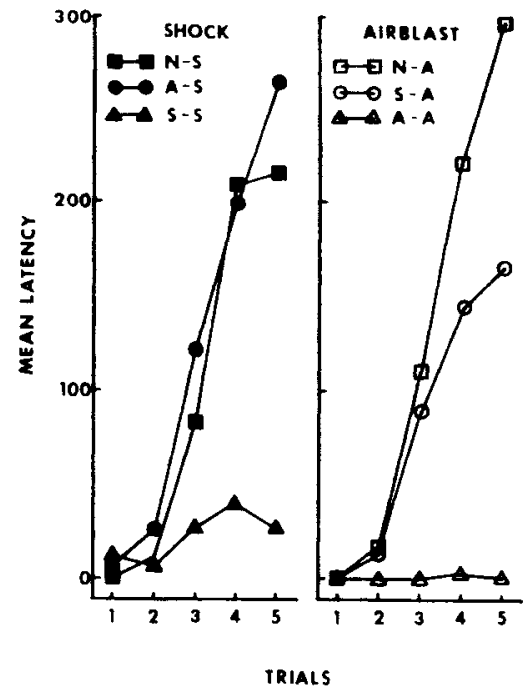

Fig. 1. Mean approach latencies during the five trials of testing as a function of training (shock, airblast, or no punishment) and testing (shock or airblast punishment) conditions.

dish of Purina wet mash located in the goal end of the runway. The $S$ was removed from the runway $45 \mathrm{sec}$ after the beginning of the consummatory response or after $5 \mathrm{~min}$ if the consummatory response was not made. On Days 2-6 of approach training each $S$ was given five massed trials similar to Trial 1 except that the animals were allowed $30 \mathrm{sec}$ of consummatory time.

The resistance training phase took place on Days 7.16 of the experiment with Ss randomly assigned to one of three training groups: gradual shock (S), gradual airblast (A), or no punishment $(\mathrm{N})$. All Ss were given two spaced trials per day with either a $1-\mathrm{sec}$ electric shock, a $1-\mathrm{sec}$ airblast, or no punishment administered when the $S$ touched the food. For the Ss in the gradual shock group the shock was introduced at $.10 \mathrm{~mA}$ and was increased by $.03 \mathrm{~mA}$ each trial until the maximum level of $.40 \mathrm{~mA}$ was reached. Only one punishment was given on each trial and Ss were allowed a maximum of $5 \mathrm{~min}$ to return to the food and eat for $30 \mathrm{sec}$. The procedure for the gradual airblast group was similar except that the airblast was started at approximately 3 psi and was increased by approximately 3 psi until the maximum level of $30 \mathrm{psi}$ was reached. The no punishment group received no punishment during resistance training.

The punishment testing phase of the experiment took place on Days 17-21 of the experiment with the $S s$ in the three resistance training groups randomly assigned to one of two testing conditions: (1) shock testing ( $S$ ) and (2) airblast testing 